\title{
Biogas Production from Anaerobic Co-Digestion of Food Waste Mixed with Domestic Wastewater
}

\author{
Supaporn Pongthornpruek ${ }^{1, a^{*}}$ and Sumanan Watmuang ${ }^{1, b}$ \\ ${ }^{1}$ Faculty of Science and Technology, \\ Uttaradit Rajabhat University, Muang, Uttaradit, 53000, Thailand \\ a Pongthornpreuk@hotmail.com, bnook190237@gmail.com \\ *Correspondence E-mail: Pongthornpreuk@hotmail.com, ajann_envi@uru.ac.th
}

\author{
Keywords: Biogas, Food waste, Wastewater, Co-digestion
}

\begin{abstract}
This research was to investigate the potential of biogas production from the co- digestion of canteen wastewater and food waste. Batch experiments were carried out under various substrate ratios $1: 1: 0,1: 1: 1,1: 1: 2,1: 2: 1,2: 1: 1,2: 2: 1,3: 2: 1,4: 2: 1,6: 5: 1,8: 5: 1$, $10: 3: 1,10: 4: 1$ and $10: 5: 1$ (canteen wastewater : swine manure : food residue waste) at room temperature. The biogas production was carried for a retention period of 7 days to investigate suitable mixing ratio. The suitable ratio was tested in a plastic container 200 liter with bath and fed-batch experiment for a retention period of 45 days. The results revealed that fermentation slurry mixing ratio of $1: 2: 1$ was found to be optimum, which gave the methane production with composition $47.34-61 \% \mathrm{CH}_{4}$. The biogas yield and thermal energy were $88.86 \mathrm{~L} /$ day and $69 \mathrm{kcal}$ respectively.These primary results indicated the significance of co-digestion of canteen wastewater with food waste for biodegradation and biogas production.
\end{abstract}

\section{Introduction}

The economic growth has led rapidly increasing energy consumption [1], with increasing prices of oil and gas the world looks towards alternative and green energy resources[2]. There is an ongoing search to develop sustainable, affordable, environmentally friendly energy from renewable sources $[3,4]$. The dependence on fossil fuel as primary energy source has led to global climate change, environment degradation and human health problems [5]. Untreated wastewater generally contains high levels of organic materials with numerous pathogenic microorganisms, trace heavy metals, nutrients and toxic compounds. Therefore, the ultimate goal of domestic wastewater treatment is to protect the environment that has impact on protection of the environment with public health and socio-economic matters [6]. Co-digestion is the simultaneous digestion of more than one type of waste in the same unit. Advantages include better digestibility, enhanced biogas production/methane yield arising from availability of additional nutrients, as well as a more efficient utilization of equipment and cost sharing [7].To improve the potential of biogas production, codigestion of organic wastes could have the potential to improve the efficiency of anaerobic digestion process[8]. The aim of this study was to investigate the potential of canteen wastewater and food waste for the methane production in laboratory scale. The effect of the feed mixing ratio on the system performance was tested in a batch experiment according to at various ratios of co-substrates and to evaluate its process performance.

\section{Materials and Methods}

\section{Sample collection}

Swine manure was collected from a local pig farm in Lablae district, Uttaradit province. Wastewater and food residue waste were obtained from canteen of Uttaradit Rajabhat University. The collected food wastes were considered impurities such as plastic, bone and fish bone. These are classified and remove by collector. 


\section{Materials/Instruments}

The materials/instruments used for the purpose of this research are as follows: weighing balance, gas chromatography, $\mathrm{pH}$ meter, thermometer, Gas analyzer, desiccators, crucibles, oven, gas collectors and biogas burner fabricated locally for checking gas flammability.

\section{Experimental procedure}

The biogas production potentials of co-digestion in this study were determined in batch and fed-batch experiment. In the first experiment, laboratory batch reactors were set up in glass vessels to sealed anaerobic digesters. A schematic diagram of biogas unit is shown in Fig. 1. All experiments were conducted with 10 conditions. The ratios of co-substrates between canteen wastewater with swine manure mixing were $1: 1: 0,1: 1: 1,1: 1: 2,1: 2: 1,2: 1: 1,6: 5: 1,8: 5: 1,10: 3: 1$, 10:4:1 and 10:5:1 respectively to determine the optimum ratio of biogas production. After filling, all digesters were closed with a rubber cap. Each biodigester is connected to a means of connecting tube. A stand holds all the gas collectors. The experiment was performed for 7 days. During the experiments, all digesters were operated at room temperature $\left(27-32^{\circ} \mathrm{C}\right)$. The volume of biogas production and gas composition were analysed until the biogas accumulation was constant. Biogas evolved is collected by downward water displacement. The biogas composition was measured by a gas chromatography (GC).The second experiment, was conducted based on the optimal mixing ratio for the biogas production selected from the results of the first experiment.The batch and fedbatch experiment was tested in a 200 liter plastic container. Co-digestion was carried for a retention period of 45 days. The effect of the feed mixing ratio to evaluate the methane production performances and its process.

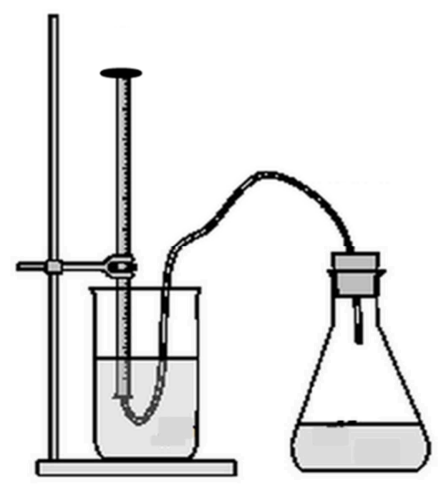

Figure 1. Schematic diagram of the digester

\section{Analytical analysis}

The samples were taken from each container before and after the experiments. The following parameters were analyzed: $\mathrm{pH}$ was measured using a glass electrode $\mathrm{pH}$ meter to monitor the $\mathrm{pH}$ of the sample. Analysis of the chemical oxygen demand (COD), total solid (TS), total suspended solid (TSS), total dissolved solid (TDS), volatile fatty acids (VFA ) and Alkalinity(mg/l) were performed according to the Standard Methods for the Examination of Water and Wastewater [9]. The biogas volume and composition were measured by the displacement of water and analyzed by gas chromatography (GC-8A Shimadzu). Thermal energy was calculated based on the equation $\mathrm{Q}=\mathrm{mc} \Delta \mathrm{T}$. The synergistic effect was calculated from the best condition.

\section{Results and Discussion}

Some substrates have limitations and appear to be low-efficient when they are degraded anaerobically. In this study, food wastes were used to avoid interferences from the minority compounds, and to analyse the viability of the co-digestion between substrates. The characteristics of the wastewater as compared to the literature reports. Domestics wastewater in this study had high COD concentration $(1400 \mathrm{mg} / \mathrm{L})$ compared to the literature reports (Bodkhe, 2009). The characteristics of wastewater in this study were shown in Table 1 
Table 1. The characteristics of the wastewater as compared to the literature reports

\begin{tabular}{|l|c|c|c|c|}
\hline Parameters & Unit & Current study & {$[8]$} & {$[10]$} \\
\hline Temp. & ${ }^{\circ} \mathrm{C}$ & 29.57 & - & - \\
\hline $\mathrm{pH}$ & - & 5.75 & 6.87 & $7.5-8.2$ \\
\hline $\mathrm{TSS}$ & $\mathrm{mg} / \mathrm{L}$ & 81.00 & 13 & $300-450$ \\
\hline TDS & $\mathrm{mg} / \mathrm{L}$ & $4,123.11$ & 311 & - \\
\hline $\mathrm{TS}$ & $\mathrm{mg} / \mathrm{L}$ & $4,655.33$ & 324 & - \\
\hline COD & $\mathrm{mg} / \mathrm{L}$ & $1,400.89$ & 516 & $350-450$ \\
\hline
\end{tabular}

\section{Fermentation slurry}

The quantity of cumulative biogas production with time for all the substrate ratios shown in Fig. 2, substrate ratio $1: 2: 1$ and 10:5:1 commenced biogas production and evolved flammable biogas. While substrate ratio 1:1:1 and 2:1:1 which serves as blank. The highest biogas yield was for ratio 1:2:1 (235 $\mathrm{ml} /$ day). This performance could be because of optimum balance between the ratio.

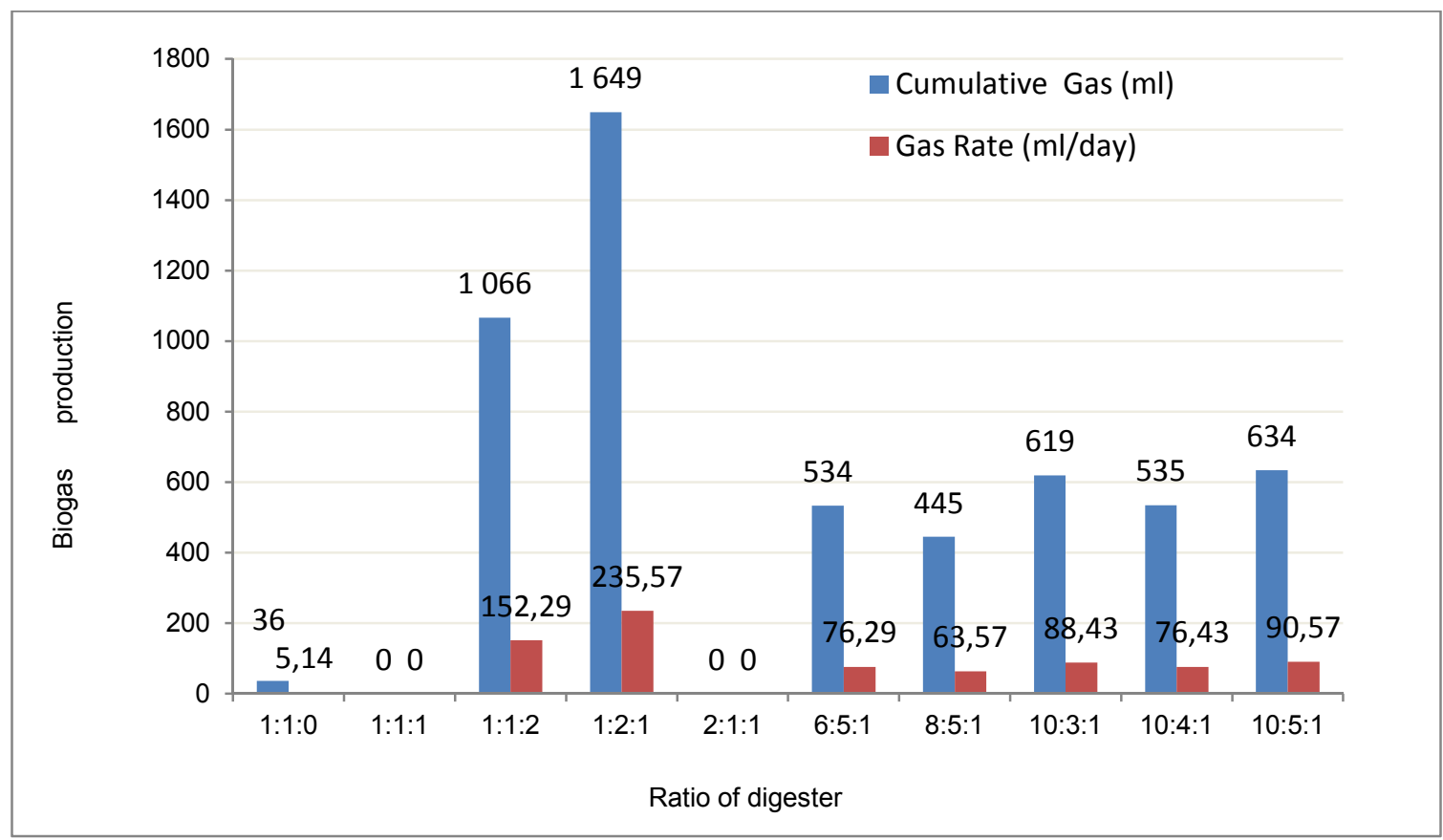

Figure 2. The quantity of cumulative biogas production for 7 days of each ratios

\section{Anaerobic co-digestion}

The batch and fed-batch experiment was tested in a plastic container 200 liter. Co-digestion was carried for a retention period of 45 days. The anaerobic process were observed of gas production. The data illustrated in Table 2 showed that the co-digester of $1: 2: 1$ with fed-batch generated 88,864L/day of biogas which was the highest amount of gas recorded throughout the study. Compare the biogas production from anaerobic co-digestion of night soil with food waste. The biogas production was 2,184 1 and $56.5 \%$ of methane fraction has obtained within 31 days of experimentation [11] 
Table 2. Gas production for 45 days in a large plastic container

\begin{tabular}{|c|c|c|c|c|c|}
\hline $\begin{array}{c}\text { Co-digestion } \\
\text { ratio }\end{array}$ & $\begin{array}{c}\text { Anaerobic } \\
\text { process }\end{array}$ & $\begin{array}{c}\text { Cumulative } \\
\text { gas }\left(\mathrm{cm}^{3}\right)\end{array}$ & $\begin{array}{c}\text { Gas rate } \\
(\mathrm{L} / \text { day })\end{array}$ & $\% \mathrm{CH}_{4}$ & \\
\hline $1: 2: 1$ & Batch & 694,216 & 46,281 & 0 & Non-flammable \\
\hline $10: 5: 1$ & Batch & 178,723 & 11,914 & 0 & Non-flammable \\
\hline \multirow{2}{*}{$1: 2: 1$} & $\begin{array}{c}\text { Fed-batch } \\
\text { every 3 days }\end{array}$ & 820,750 & 54,716 & 22.00 & Non-flammable \\
\cline { 2 - 6 } & $\begin{array}{c}\text { Fed-batch } \\
\text { everyday }\end{array}$ & $3,998,882$ & 88,864 & 47.34 & flammable \\
\hline
\end{tabular}

Table 3. The characteristics of the fermentation slurry after digestion

\begin{tabular}{|l|c|c|c|}
\hline \multicolumn{1}{|c|}{ Parameters } & Start up & $\mathbf{1 5}$ days & 45 days \\
\hline $\mathrm{pH}$ & $8.23 \pm 0.05$ & $6.67 \pm 0.02$ & $7.29 \pm 0.04$ \\
\hline Temp. $\left({ }^{\circ} \mathrm{C}\right)$ & $30.50 \pm 0.17$ & $30.17 \pm 0.06$ & $30.97 \pm 0.12$ \\
\hline VFA $(\mathrm{mg} / \mathrm{l})$ & - & $2,325.00 \pm 75.00$ & $366.67 \pm 76.38$ \\
\hline Alkalinity $(\mathrm{mg} / \mathrm{l})$ & - & $2,133.33 \pm 10.08$ & $1,233.33 \pm 76.38$ \\
\hline COD $(\mathrm{mg} / \mathrm{l})$ & $26,666.67 \pm 12,220.20$ & $34,666.67 \pm 24,440.40$ & $6,186.67 \pm 184.75$ \\
\hline TS $(\mathrm{mg} / \mathrm{l})$ & $7,880.00 \pm 423.00$ & $14,098.00 \pm 716.59$ & $7,519.33 \pm 80.16$ \\
\hline
\end{tabular}

\section{Conclusion}

The fermentation slurry mixing ratio of $1: 2: 1$ was found to be optimum, which gave the methane production with composition $47-61 \% \mathrm{CH}_{4}$. The biogas yield and thermal energy were $88.86 \mathrm{~L} /$ day and $69 \mathrm{kcal}$ respectively. The co-digestion of canteen wastewater with food waste by fed-batch everyday that had significant improvement on biogas production.

\section{Acknowledgements}

I would like to thank the Energy Policy and Plannig Office (EPPO) for financial support in this research.

\section{References}

[1] Zhang P, Lin CJ, Liu J, Pongprueksa P, Evers SA, Hart P. Biogas production from brown grease using a pilot-scale high-rate anaerobic digester. Renewable Energy 2014; 68: 304-13.

[2] Hill DT., Simplified Monod kinetics of methane fermentation of animal wastes, Agricultural Wastes, 5, 1-16 (1983).

[3] Deublein, D. and Steinhauser, A. Biogas from waste and renewable resources: An introduction. Wiley-V CH, Weinheim, Germany (2008).

[4] Khanal, S.K. Bioenergy generation from residues of biofuel industries. Anaerobic Biotechnology for Bioenergy Production: Principles and Applications. Wiley-Blackwell, Oxford, UK; John Wiley \& Sons, New York, NY, USA, (2008).161-188.

[5] Budiyano, I N Widiasa, Johari and S Sunarso., The kinetic of biogas production rate from cattle manure in batch mode,International Journal of Chemical and Biomolecular Engineering, 3(1), 39-44 (2010).

[6] Al-Sarawym A, El-Sherbiny, F and Mels, R. Coagulation andflocculation of domestic sewage with organic polyelectrolyte.Alex Engineer Journal, (2001). 40(5):777-82.

[7] Wu, X., Yao, W., Zhu,J. and Miller, C., Biogas and CH4 productivity by co-digesting swine manure with three crop residues as an external carbon source. Bioresource Technology 101, 4042-4047. (2010). 
[8] Cheerawit R, Thunwadee T, Duangporn K, Tanawat R, Wichuda K. Biogas production from Co-digestion of domestic wastewater and food waste. Health and the Environment Journal 2012; 3(2): 1-9.

[9] APHA, AWWA and WPCF, "Standard methods for the examination of water and waste water", Washington D.C, 19,2005

[10] Bodkhe, S.Y. (2009). A modified anaerobic baffled reactor for municipal wastewater treatment. Journal of Environmental Management, 90: 2488-2493.

[11] Assadawut Khanto and Peerakan Banjerdkij.(2016) Biogas Production from Batch Anaerobic Co-Digestion of Night Soil with Food Waste. EnvironmenAsia, 9(1) : 77-83 